\title{
DIFFERENT STROKES FOR DIFFERENT FOLKS: ACCESS AND TRANSPORT CONSTRAINTS FOR PUBLIC TRANSPORT COMMUTERS IN GAUTENG PROVINCE, SOUTH AFRICA
}

\author{
James Chakwizira', Peter Bikam ${ }^{2}$, Thompson Aina Adeboyejo ${ }^{3}$ \\ 1,2 University of Venda, School of Environmental Sciences, Thohoyandou, South Africa \\ ${ }^{3}$ Ladoke University of Technology, Department of Urban and Regional Planning, Nigeria
}

Received 15 December 2017; accepted 26 January 2018

\begin{abstract}
This paper seeks to illustrate differentiated access and transport constraints faced by public transport commuters in Gauteng province, South Africa. Drawing from a one thousand five hundred and fifty (1550) randomized household sample conducted in Gauteng province, South Africa, different access strokes and constraints are discussed. In any case, these findings are benchmarked and analysed in the context of the national household travel survey (NHTS) 2013 findings that was conducted by the Department of Transport (DoT). The major findings highlight differentiated commuting access and transport constraints in Gauteng province. The analysis highlights the existing of differentiated access and transport constraints for public transport commuters in Gauteng province. The driving group has to deal with problems of traffic congestion, road rage, travelling time and travel delay among other issues. The public transport group in addition to long commuting distances, travelling times has to deal with low service levels, off-peak infrequent to non-existing service, crime as well as challenges associated with non-scheduled transport systems. There is therefore, differentiated access and transport problems for public transport users who make use of the three main different modes, namely train, bus and minibus taxis. Implementing a raft of integrated, smart, transit orientated development (ToD), appropriate land use, public transport policy and action measures has potential to relieve the different transport access strokes and constraints in the study area.
\end{abstract}

Keywords: access, constraints, transport, commuters, Gauteng, South Africa.

\section{Introduction}

The scale of today's urban context is complex and bringing a new set of challenges that normally prove difficult to grasp and resolve. One interesting dimension is the reality that contemporary urbanisation in developing countries such as South Africa is concentrated in urban areas - which spatial areas are "bright lights" of "hope and despair", representatives of "power, glamour and divisions". Even more challenging is the fact that today's urban growth is happening in a context of observed urban poverty and deprivation in metropolitan areas. Indeed the cities have the potential to either integrate or separate. The concept of the "right to the city" brings exciting dimensions and

${ }^{1}$ Corresponding author: james.chakwizira@univen.ac.za 
access and constraints readings especially placed in a context of seeking to understand differentiated transport issues in a geographical setting. Post-apartheid Gauteng metropolitan areas such as Johannesburg, Tshwane (Pretoria) and Ekurhuleni are struggling with spatial transformation, land use and transport integration, crime, fear and segregation among other challenges. Locating the impact and implications of evolving transport challenges for different classes of urban commuters is essential in generating targeted and integrated interventions and solutions.

South Africa's Gauteng metropolitan province commuters face challenges that can be traced to the apartheid geography, post-apartheid policy disconnects as well as rapid urbanisation challenges (Department of Transport, 2010). Consequent to apartheid spatial fragmentation induced geography, metropolitan densities overall are very low in international terms. This results in high costs of infrastructure provision, long and costly travel for individuals, inefficient logistic networks, and low market thresholds (Department of Transport, 2005; Chakwizira, 2007; CSIR, 2010; Department of Transport, 2011; Chakwizira et al., 2011; Tadić et al., 2015). Paradoxically, the density gradient is frequently inverted which means that the highest densities are found in pockets of low-income settlements along the periphery, rather than closest to the urban centre. As a result most people in Gauteng province live far from the city centre and their place of work. The spatial fragmentation of the labour market reinforces and disperses available work (Bertaud, 2004; Bertaud, 2008). Overall, the spatial fragmentation manifests itself in spatial mismatches between residential areas and areas of "economic opportunity". South
Africa's metropolitan areas have an average density of 2960 people $/ \mathrm{km}^{2}$, compared with 8292 people $/ \mathrm{km}^{2}$ for low- and middle-income countries and 3100 people $/ \mathrm{km}^{2}$ for highincome countries (CSIR, 2010; SACN, 2011). Internationally, the only cities with lower average densities than South African cities, and longer travel distances to work, are the sprawling cities of North America, which rely heavily on individual passenger cars rather than public transport (Shrank et al., 2012). However, since the early 1990s, a growing concentration of people living in inner-city Johannesburg, Tshwane (Pretoria) and Ekurhuleni has begun to counteract the distortion of a negative density gradient. In many cases, this is happening through informal processes such as increased densities in informal settlements close to work, and growing numbers of backyard shacks (Department of Transport, 2011; Balya et al., 2016). In this context different sets of access and constraints for commuters emerge which make travelling experience difficult and painful - presenting what we call different strokes for different folks in Gauteng province. The Oxford dictionary defines a stroke as an act of hitting or striking someone or something; a blow and or to be stuck. In this paper the notion of access and constraints strokes relate to problems or challenges that are hitting, blowing or striking and the act of urban public transport commuters being stuck in transport problems in Gauteng province.

\section{Literature Review: Access and Constraints Debates}

A review of literature indicates that World urban land use and transport systems and theories to addressing access and constraints to public transport commuting can be reduced to a binary land use and transport approach 
that is based on either a low density or high density urban theoretical and philosophical approach. Table 1 summarizes the two major world urban transport paradigm systems used in responding to commuting matters highlighting the major differences which have implications for access and constraints in any geographical setting.

\section{Table 1}

\section{A Comparison of Two Major World Urban Land Use and Transport Systems}

\begin{tabular}{|c|c|}
\hline $\begin{array}{l}\text { Low density land use and transport development } \\
\text { systems }\end{array}$ & $\begin{array}{l}\text { High density land use and transport development } \\
\text { systems }\end{array}$ \\
\hline $\begin{array}{l}\text { Zoned development } \\
\text { Segregation of functions for living, working, recreation } \\
\text { functions }\end{array}$ & $\begin{array}{c}\text { Mixed-use development } \\
\text { Integration of functions for living, working, recreation } \\
\text { Mixed-income communities }\end{array}$ \\
\hline Segregation of demographic and economic groups & Integration of functions for living, working, recreation \\
\hline $\begin{array}{c}\text { Car dependence } \\
\text { Disconnected and fragmented public spaces } \\
\text { High-speed transport networks and increased road } \\
\text { infrastructure } \\
\text { Planning for Parking, buildings and freeways Parks, } \\
\text { landscaping and cycle paths } \\
\text { Minimum parking spaces' requirement for new } \\
\text { developments } \\
\text { Sense of anonymity }\end{array}$ & $\begin{array}{c}\text { Predominance of pedestrians and cyclists } \\
\text { Interconnected walkable network of large- and small- } \\
\text { scale public spaces } \\
\text { Minimised need for transport and increased road } \\
\text { infrastructure } \\
\text { planning for walking and cycling } \\
\text { Planning for Parks, landscaping and cycle paths } \\
\text { Parking space capping requirement for new developments } \\
\text { Sense of community }\end{array}$ \\
\hline $\begin{array}{l}\text { United States of America urban model } \\
\text { Developed from about } 100 \text { years ago }\end{array}$ & $\begin{array}{c}\text { European/Asian model } \\
\text { Developed from about } 9,000 \text { years ago }\end{array}$ \\
\hline $\begin{array}{c}\text { Large Scale Developments } \\
\text { Superstores and big shopping complexes } \\
\text { Unlimited retail space per commercial/industrial districts } \\
\text { groceries and shopping complexes } \\
\text { Unlimited retail space per occupier } \\
\text { Mass housing }\end{array}$ & $\begin{array}{c}\text { Neighbourhood/human scale developments } \\
\text { Mixed-use and mixed-income shopping complexes } \\
\text { Capping of allowable space for retailers to preserve } \\
\text { neighbour-hood scale } \\
\text { Mixed-use and mixed-income } \\
\text { Corner shops, local shopping areas, farmer's markets }\end{array}$ \\
\hline Driven by market forces & Driven by vision and master-plan \\
\hline High energy & Low energy \\
\hline High $\mathrm{CO}_{2}$ emissions & Low $\mathrm{CO}_{2}$ emissions \\
\hline \multicolumn{2}{|c|}{$\begin{array}{l}\text { Implications for differentiated transport strokes and folks "What hits, strikes, blows and how public } \\
\text { transport commuters are stuck" in a vicious circle of commuting problems }\end{array}$} \\
\hline Negative Impacts and consequences & Positive Impacts and consequences \\
\hline $\begin{array}{c}\text { Long commuting distances } \\
\text { Long commuting times } \\
\text { Sprawled settlements and fragmentations } \\
\text { Loss of family and social time } \\
\text { High commuting costs and tariffs } \\
\text { Commuting in travel time problems e.g. accidents, traffic } \\
\text { congestion, road rage etc. } \\
\text { High public transport subsidies } \\
\text { Ad-hoc and fragmented stakeholders responses }\end{array}$ & $\begin{array}{c}\text { Short commuting distances } \\
\text { Short commuting times } \\
\text { Integrated and spatially better networked settlements } \\
\text { Quality family and social time } \\
\text { Low/affordable/competitive commuting costs/tariffs } \\
\text { Pleasurable in travel experiences } \\
\text { No, low or sustainable public transport subsidies } \\
\text { Integrated, adaptive institutional and stakeholders } \\
\text { responsive systems }\end{array}$ \\
\hline
\end{tabular}

Source: (Silverman, 2007; Office of Science and Technology, 2006; UITP, 2006; UITP, 2012; Hjaltested, 2012)

Experiences from London, Hamburg, Munich, Moscow, Barcelona and Rome, show that public transport vehicles travel faster than car traffic provided the right set of conditions are provided (Vivier, 2006; UITP, 2012). In addition, the major role played by rail transport 
in making public transport a travelling mode of choice (which provides over $70 \%$ of supply in these cities, save for Rome) is the main reason why commuting experiences are less painful for travelers in developed countries as compared to counterparts in developing countries (UITP, 2015). Adverse traffic conditions help the competitiveness of public transport in Rome and in London. Heavy investment in rail network (usually above 50\%) is usually a fore-runner to enhanced public transport performance and service delivery (Vivier, 2006; UITP, 2012). In such cases the line speed of public transport is close and competitive enough to that of cars. This is the case in German cities as well as in French and Spanish cities with a metro system, and in Oslo, Copenhagen, Brussels, Bern, Zurich, Vienna, Budapest and Prague. It should also be realized that the strong public transport competitiveness in Lisbon, Athens and Hong Kong, where buses are the main provider, is as much down to the difficulties facing traffic as it is to the speed of public transport (Vivier, 2006).

Reflecting on public transport shifts over the last century, Litman and Burwell (2006) identify a shift which bordering on the reduction of private automobile dependency in favour of public transport based travel alternatives. The overall lesson from the literature scan is that investment in public transport are not a once of event or a touch and go affair if commuting challenges are to be reduced. Sustainable commuting challenges resolution requires the application of a prudent game change making tactics and processes structured around catalytic interventions aimed at promoting universal if not pro-poor public transport modal shift which breaks reliance on the use of private cars for travel in the city. Transport and related transport interventions should be backed by a solid transport vision, strategy and sustainable funding and adaptive governance systems (Chakwizira and Mashiri, 2009). Ultimately, a sustainable mobility turn-around require a major paradigm shift from transportation systems designed to move vehicles to ones that are designed to move people if transport commuter pains are to be removed. In addition, even where low-cost technical solutions exist, institutions are the ultimate determinant of successful implementation (UITP, 2010; Litman, 2010; Balya et al., 2016). Consequently, efforts to bring change must focus on the institutions, governance and attitudes and not just technical solutions.

\section{Research Objectives and Methodology}

This section presents the research objectives and research methodology employed in studying commuting access and constraints in the Gauteng province, South Africa.

\subsection{Research Objectives}

The principal research goal of the research was to investigate access and constraints to urban public transportation systems in the Gauteng Province of South Africa with a particular focus on highlighting the travelling burden and pains experienced by public transport commuters (Chakwizira, 2016). Two main objectives were generated to facilitate the realization of the principal research goal, which are namely:

1. Identify the major public transport commuting challenges in Gauteng province (i.e. Ekurhuleni, Tshwane (Pretoria) and Johannesburg); and

2. Explore measures and actions that can be used to resolve commuting challenges in Gauteng province (i.e. Ekurhuleni, (Tshwane (Pretoria) and Johannesburg). 


\subsection{Research Methodology}

This paper discusses an extract of results and findings from a primary data set of a larger research sample frame comprising a randomized household access survey of 1550 units in Gauteng province, South Africa (Chakwizira, 2016). The randomized household access survey was made up of 150 (representing $9.6 \%$ of the total sample size) household apiece for Pretoria CBD (mixed income), Mamelodi (low income), Pretoria East (high income), Mabopane (low income), Hammanskraal (low income) and Midrand (high income) and Johannesburg CBD (mixed income) with 100 households (representing 6.4\% of the total sample size each), Tembisa (low income), Soweto (low income), Alexandra (low income) and Sandton (high income) 150 (representing $9.6 \%$ of the total sample size each) (Chakwizira et al., 2014). The study adopted the Gauteng province as a case study. This was informed by the fact that Gauteng is the most urbanized part of South Africa and experiences sharp urban transport commuting challenges making it a good candidate to understand different transport strokes for different folks in the South African context. A thematic approach is employed in analyzing the access and constraints to commuting in Gauteng province making use of the following variables, socio-economic demographics (i.e. gender, highest education, household car ownership, household income, expenditure on public transport), modal choice (most frequent trips, modal split of trips), commuting challenges and problems (i.e. problems with public transport, distances of residences from socio-economic opportunity areas, travelling time to socio-economic facilities, time that commuters leave home for work, travel interchanges and traffic congestion). Descriptive statistics measuring the mean, mode and mean are employed in further analyzing the data. In any case the travel time index (TTI) technique is used in summarizing the access and constraints to commuting in the study area (Eisele et al., 2011).

\section{Discussion of Results and Findings}

\subsection{Gauteng Province: Unraveling the Commuting Context}

Gauteng province is a cosmopolitan region that draws people from South Africa, Southern African Development Community (SADC) and the larger international community (Chakwizira, 2016). This is made possible by the fact that it is an economic hub that has the unique characteristics within its boundaries of three metros (Johannesburg, Tshwane (Pretoria) and Ekurhuleni) in addition to two district municipalities.

In terms of the Gauteng Spatial Development Framework (GSDF) the Provincial Economic Core is anchored by Rosslyn to the north (Tshwane) and is linked to the Johannesburg International Airport to the east (Ekurhuleni) via the N1/R21 and the Central Business District of Johannesburg to the south via the N1/M1 highway' (Chakwizira, 2016). This emerging Gauteng Urban Region and its strategic prominence is a very strong force that shapes the Province's form spatially, economically and institutionally. Gauteng province is therefore referred to as a polycentric region which is characterized by functional specialisation and differences in scale between the dominant centres (i.e. Johannesburg, Ekurhuleni and Tshwane (Pretoria)) and within their overlapping hinterlands (Harrison et al., 2008). Indeed, 
The Gauteng province is a rapidly urbanizing region. The South African population has grown by more than $15 \%$ between 2001 and
2011 (Chakwizira, 2016). Within the same period, Gauteng has grown 30\% during this period (refer to Figure 1).

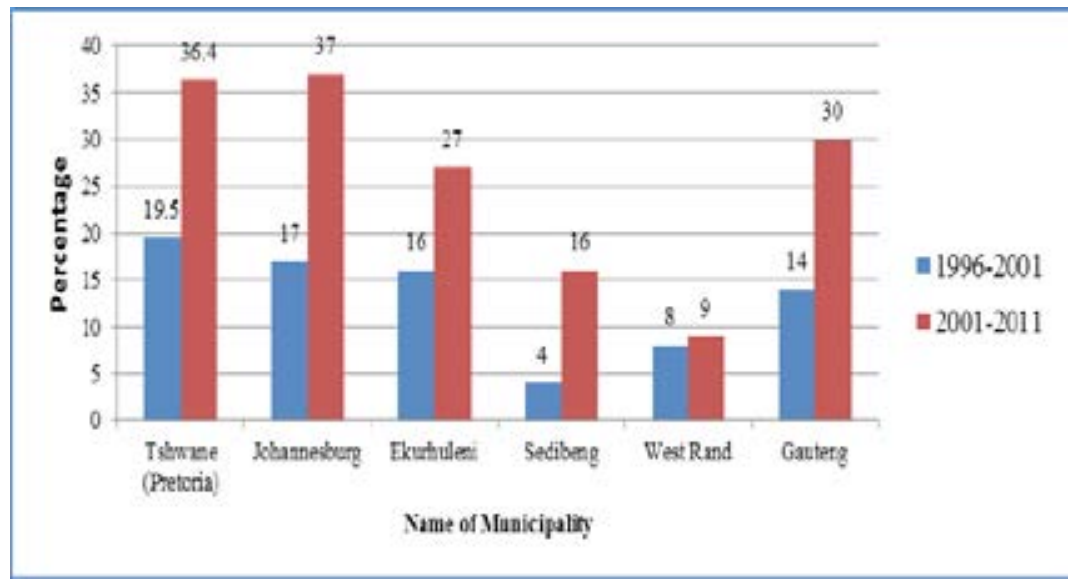

Fig. 1.

Population Growth in Gauteng Province, South Africa

Source: (StatsSA, 2014)

In addition, the population of Gauteng province is spread over a wider area. This means that the development density of the province is lower if compared with many cities in the World. The diameter of the circle that contains the combined urban area of the three metropolitan municipalities in Gauteng is $112 \mathrm{~km}$ compared with $45 \mathrm{~km}$ in the case of London (Chakwizira, 2016) (refer to Table 2). This also shows the difference between the development densities in Gauteng and London (Gauteng Department of Roads and Transport (GDRT), 2013).

Table 2

Population and Development Densities - Gauteng Metropolitan Areas Versus Landon and Paris

\begin{tabular}{|l|c|c|c|c|c|}
\hline City & Year & Population & Area (ha) & Diameter $(\mathbf{k m})$ & Density (Persons/ha) \\
\hline Gauteng Metros & 2010 & 9436866 & 983012 & 112 & 9.6 \\
\hline London & 2010 & 7800000 & 157900 & 45 & 49.4 \\
\hline Paris & 2010 & 6500000 & 76200 & 31 & 85.3 \\
\hline Gauteng Metros & 2037 & 16408617 & 983012 & 112 & 16.7 \\
\hline
\end{tabular}

Source: (Gauteng Department of Roads and Transport (GDRT), 2013)

The relative low density and sprawled nature in Gauteng poses interactions implications within and across the metropolitan cities in the province. This has been singled out for causing great inefficiencies and high investment costs in attempts to serve the area effectively with a variety of services, including transport (Chakwizira, 2016). 


\subsection{Socio-Economic Demographics of Public Transport Commuters in Gauteng Province}

\subsubsection{Gender Spatial Distribution in Gauteng Province}

Spatially, a high concentration of male respondents were recorded in Alexandra 104 (6.71\%); Hammanskraal and Mamelodi 78 (5.03\%) apiece; Mabopane 89 (5.74\%); Pretoria Central 88 (5.5\%) and Johannesburg Central 61 (3.94\%). These areas have traditionally been dominated by migrant male labour. This is also a reflection of high male headed family units in the study area as the questionnaire targeted household family heads (Chakwizira, 2016). Low female respondents participants were recorded in Midrand 33 (2.13\%); Johannesburg Central 39 (2.52) and Mabopane 61 (3.94\%).

\subsubsection{Highest Education Attained Spatial Footprint in Gauteng Province}

Gauteng has mixed people (labour) which has different sets of knowledge and skills. This relates to educational and post-education training. Overall, survey participants profile are indicative of the fact that respondents are literate and were able to interact with the researchers and also have a sound grip of transport commuting and related matters, which constituted the heart of the research investigation work (Chakwizira, 2016). 10 (0.6\%) of the survey respondents had received no schooling. 19 (1.2\%) of the survey respondents had Grade 6 education. Those with grade 12 were 395 representing $25.5 \% .658$ (42.5\%) had received vocational education; 329 (21.2\%) had a Junior Degree; $111(7.2 \%)$ had a Bachelor Degrees while 28 (1.8\%) had post-graduate qualifications.

\subsubsection{Household Car Ownership}

The household car ownership mean from the survey is $0.53 .64 .8 \%$ of the survey respondents do not own any car. $24.6 \%$ of the survey respondents owned a car, while $7.7 \%$ of the survey household respondents owned 2 cars (Chakwizira et al., 2014). 1.7\% of the survey respondents owned more than three cars in a household. Households that own four or more cars constituted $0.3 \%$ and $0.9 \%$ respectively. The bulk of respondents from high density areas such as Mamelodi (110 i.e. $71 \%$ of the sampled 150 respondents in the area), Tembisa (118 i.e. $76.1 \%$ of the sampled 150 respondents in the area), Soweto (104 i.e. $67.1 \%$ of the sampled 150 respondents in the area), Mabopane (97 i.e. $62.6 \%$ ) and Hammanskraal (110 i.e. $71 \%$ ) did not own a car. The highest ownership of cars was found in Pretoria Central (48.4\%), Pretoria North (55.5\%), Pretoria East (45.5\%), Sandton (35.5\%) and Johannesburg Central (63.9\%). The areas with higher car ownership are traditionally more affluent areas of the cities. At the same time the areas with low car ownership are traditionally low income areas. While the high car high income areas can be located far away from economic nodes, the residents own private cars and are able to overcome distance access challenges. However, the same cannot be said of peripheral low car ownership and low-income areas who have to endure both long travelling times and high costs save for those who use the subsidized buses and or metro train.

\subsubsection{Household Income in Gauteng Province}

An understanding of the household income is essential in understanding travel suppression or enhanced mobility in a geographical space. 
$65,5 \%$ of the respondents earn below rands R9000 (€690) a month (Chakwizira, 2016). A significant $54,9 \%$ of the respondents earn below R7000 ( $€ 536)$ a month, while $33,6 \%$ of the respondents earn less than R5000 (€383) a month. In terms of spatial distribution, high earning suburbs included Pretoria Central, Pretoria North, Pretoria East, Midrand, Sandton, Johannesburg and as outliers Tembisa and Soweto. Spatially as expected the majority of pro-poor transport commuters are located in low income peripheral areas such as Mamelodi, Mapobane, Hammanskraal, Soweto and Tembisa (Chakwizira et al., 2014).

\subsubsection{Expenditure on Public Transport in Gauteng province}

In terms of the survey results expenditure on public transport was below rands R 1000 $(€ 76)$ for $77 \%$ of the respondents. This is because the majority of the respondents walked or used subsidized metro and bus services. $23 \%$ of the respondents used upwards of R1001 (€77) on public transport. More than half of South African households $(56,8 \%)$ have a total monthly expenditure of R1799 (€138) or less. A further $25,1 \%$ spent between R1800 ( $€ 139)$ and R4999 (€385) on a monthly basis (StatsSA, 2014). The multidimensional nature of poverty manifests itself in terms of various aspects relating to urban transport, access, and exclusion: The income poor make fewer trips, and more of their trips are undertaken on foot. For most purposes they are restricted to whatever services (usually poor) can be accessed within walking distance, making them accessibility poor. The journey to work may be relatively long. Even if it is not, it will use slow modes and may be very time consuming, so they are also time-poor. For poor people, and particularly for women, children and the elderly, trip making is often discouraged by their vulnerability as pedestrians both to traffic accidents and to personal violence, making them safety poor (Chakwizira, 2016). Finally there is evidence that long walking distances and times also creates a loss of quality social and family time, tiredness and boredom adding an energy-poverty dimension to their deprivation. Table 3 presents survey respondents public transport expenditure in Gauteng.

\section{Table 3}

Survey Respondents Public Transport Expenditure in Gauteng

\begin{tabular}{|c|c|c|}
\hline Amount Spent & Frequency & Valid Percent \\
\hline R0-R500 $(€ 0-€ 38)$ & 751 & 48.5 \\
\hline R501-R1000 $(€ 39-€ 77)$ & 442 & 28.5 \\
\hline R1001-R1500 $(€ 78-€ 115)$ & 65 & 4.2 \\
\hline R1501-R2000 (€116-€154) & 20 & 1.3 \\
\hline R2001-R2500 (€155-€192) & 35 & 2.3 \\
\hline R2501-R3000 (€193-€231) & 9 & 0.6 \\
\hline More than R3000 (€232) & 12 & 0.8 \\
\hline N/A & 214 & 13.8 \\
\hline Staff & 2 & 0.1 \\
\hline Total & $\mathbf{1 5 5 0}$ & $\mathbf{1 0 0 . 0}$ \\
\hline
\end{tabular}

Note: Exchange rate during time of study was $1 €$ equivalent to ZAR13 
However, transport expenditure for private motorists is higher than for those who use public transport which is expected. 139 (9\%) of the respondents spent more than $\mathrm{R} 3000$. $21 \%$ of the respondents spent more than $\mathrm{R} 1501$ on private transport expenditure.

\subsection{Modal Choice}

\subsubsection{Most Frequent Trips}

In terms of survey respondents, $82.5 \%$ of the trips are work based. The remainder of $17.5 \%$ is made up of $2.39 \%$ (trips to other residential suburbs), $1.815 \%$ (school trips), $1.94 \%$ (shopping trips), $4.13 \%$ (private business trips), $1.61 \%$ passenger service and others $1.48 \%$. An analysis, of the national household and travel survey (NHTS), 2003, 2011 Gauteng City Region Observatory (GCRO) and 2013 Survey Results reveal that the main change in school transport over the last ten years appears to be an increase in school bus trips, at the expense of walking, otherwise mode share has remained more or less the same (StatsSA, 2014).

\subsubsection{Modal Split Comparison of National Household Travel Study (NHTS) 2003 and 2013}

A closer examination of the NHTS 2003 and 2013 results yields useful revelations. Car users have increased by $5.8 \%$ from $28.5 \%$ in 2003 to $34.2 \%$ in 2013 . This reflects the growth in the middle class as well increased car ownership owing to a combination of reasons such as access, status symbol and poor performance of the public transport system. Those who walk reduced from $32.5 \%$ to $25.8 \%$ a percentage reduction of $6.5 \%$. This can be explained two folds. Despite the fact that Gauteng cities are not pedestrian friendly cities, this could be a result of the impact of reconstruction development programme (RDP) subsidized new housing as well as suburban development being located at the periphery and away from the major nodes in the Gauteng. Both the mass movers of transport that the Department of Transport public transport policy of 2007 seeks to promote recorded negative growth. This is worrying as it may indicate the need to bolster and inject more investment to make these modes dynamic and be at sync with the commuting needs. The implementation pace at which integrated rapid public transport network (IRPTN) and plans are being rolled out nationally need to be fast tracked. The metro train declined by $0.5 \%$ from 7.1 to $6.6 \%$. One would have expected some gains given that Gautrain has started to operate and has made in-roads especially in the middle and high income groups who travel between Pretoria, Sandton, Johannesburg and OR Tambo airport (Kempton area). The handicap is that this initiative is only in one Province of the Country. The other explanation is that there is transferred and displaced trips since with the Gauteng freeway improvement and Gautrain the created space has been filled by those who used public transport to bring back their cars on the roads including the impact of new car sales. The taxi mode has remained the main mode of public transport and gained $2.6 \%$ from $22.5 \%$ in 2003 to $25.1 \%$ despite a host of known shortcomings of this service. The ability to penetrate and offer more flexible services is at the heart of this outcome. The challenge in improving public transport is how to transfer people from taxis and private cars to buses and trains. The other option is how to integrate the minibus taxi to act as 
a feeder service to the bus and rail service as part of total transport integration solutions. Figure 2 presents the modal split comparison between the NHTS, 2003 and 2013 results.

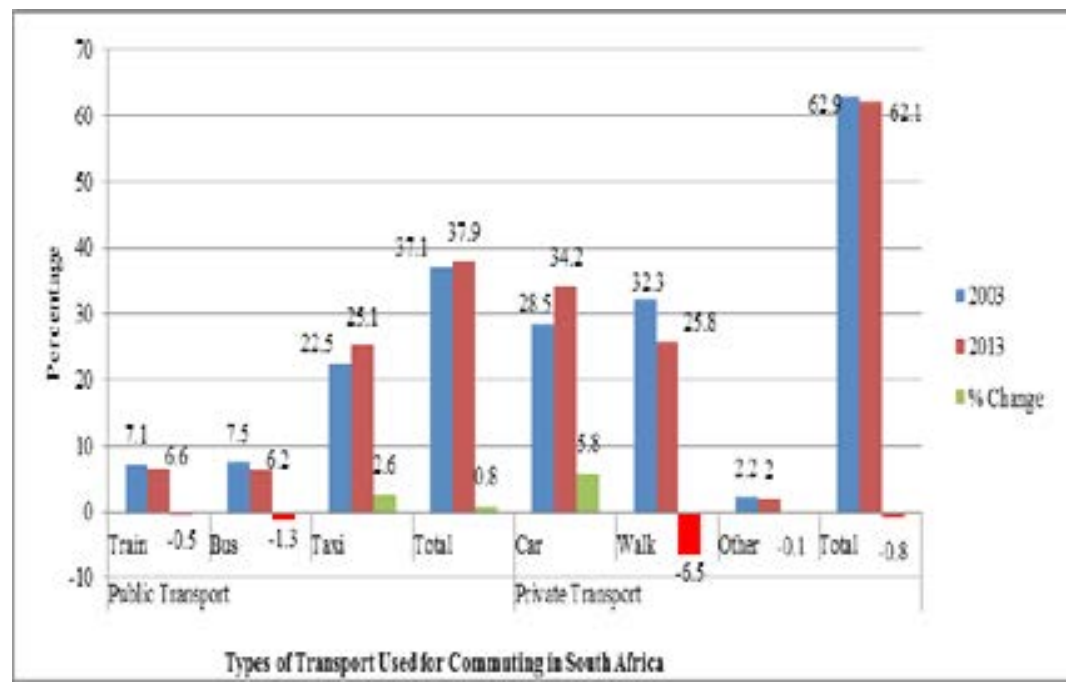

Fig. 2.

Modal Split Comparison 2003 and 2013

Source: (StatsSA, 2014; Department of

Transport, 2013)

\subsection{Commuting Challenges and Problems with Public Transport in Gauteng Province}

\subsubsection{Problems with Public Transport in Gauteng Province}

Overall, 330 (21.3\%) of the respondents indicated that the problem of public transport is that the fares are high. This is quite contradictory given that the fares are subsidized save for the mini bus taxi (Chakwizira et al., 2014). 228 (14.7\%) of the survey respondents highlighted that long walking distance to the nearest public transport station hindered commuting and created use and access problems. 511
(33\%) singled out the long waiting times at public transport ranks/stops/terminuses as a serious constraint in the use of public transport. 146 (9.4\%) highlighted that generally public transport such as metro train, buses and mini-bus taxi were not reliable. Spatially, the problem of high fares was cited in all low income peripheral settlements, namely Mamelodi 64 (41.3\%); Mabopane 63 (40.6\%); Hammanskraal 64 (41.3\%); Tembisa 20 (12.9\%) and Soweto 39 (25.2\%). Incidentally the same settlements had problems with long walking distances to public transport bus stops/train stations, Mamelodi 22 (14.2\%); Mabopane 17 (11.0\%); Tembisa 41 (26.5\%); Soweto 16 (10.3\%) and Alexandra 23 (14.8\%) (Chakwizira, 2016). Another decisive constraint is long waiting times at public transport stop/terminuses (StatsSA, 2014). This problem pervades all 
spatial areas and is a generic problem for all public transport modes. Pretoria central recorded 48 (31\%) of the survey respondents who indicated that this was a big problem with public transport. Mamelodi $36(23.2 \%)$; Pretoria East 50 (32.3\%); Mabopane 36 (23.2\%); Midrand 37 (23.6\%); Tembisa 35 (22.6\%); Sandton and Alexandra 70 (45.2\%) and Soweto 52 (33.5\%) complete the picture regarding how long commuters wait at stations before service is rendered (Chakwizira, 2016).

\subsection{Spatial Fragmentation and Commuting Loop Challenges in Gauteng Province}

\subsubsection{Distances of Residences from Socio-Economic Opportunity Areas}

The distance of settlements from socioeconomic opportunity areas such as industrial and commercial nodes is a reflection of the spatial structure's level of efficiency and compactness (Bertaud, 2004). Bertaud, 2008 indicates that spatial deficiency manifest itself in terms of commuting distances for a significant part of the population being either too long to be travelled within a reasonable travel time or/and at a reasonable cost. In addition, the spatial distribution of population and the pattern of trips are incompatible with the main mode of transport affordable to the poor.

Survey respondents overall indicated that the distance to socio-economic opportunity areas in Gauteng is fair (i.e. 800 (51.6\%) to long (i.e. 603 (38.9). Only 136 (8.7\%) of the survey respondents indicated that the distances are short. $3(0.2 \%)$ did not know about travel distances while 4 (0.3\%) indicated that distances varied depending with the route one used. Short distances were defined as $0-15 \mathrm{~km}$. Fair distance was defined as $16-30 \mathrm{~km}$. Long distance was defined as $31 \mathrm{~km}$ and above. This categorization was adopted from the National Land Transport Strategic Framework 2006-2011 travel benchmark (Chakwizira, 2016). The survey respondents are attuned to other research findings. Compared to 2003, more households in the metropolitan areas travelled more than 60 minutes to get to all types of facilities in 2013. More than $20 \%$ of households travelled more than 60 minutes to reach other shops (20.5\%) and traditional healers (26.5\%). Approximately $13 \%$ of households travelled more than 60 minutes to a medical service compared to $6.6 \%$ of households in 2003 Department of Transport (2013). The National Land Transport Strategic Framework set certain targets for urban access indicators, namely: average travel time to work should be less than about 1 hour; a ratio of 80:20 between public transport and private car use; and affordable public transport with commuters spending less than about 10 per cent of disposable income on transport. In addition, commuters in urban areas should have access to public transport within 1 kilometer (about a 15 minute walk) (Gauteng Department of Roads and Transport (GDRT), 2013). Figure 3 presents a graphical illustration of survey respondent's distances of residences to socioeconomic areas in Gauteng province. 


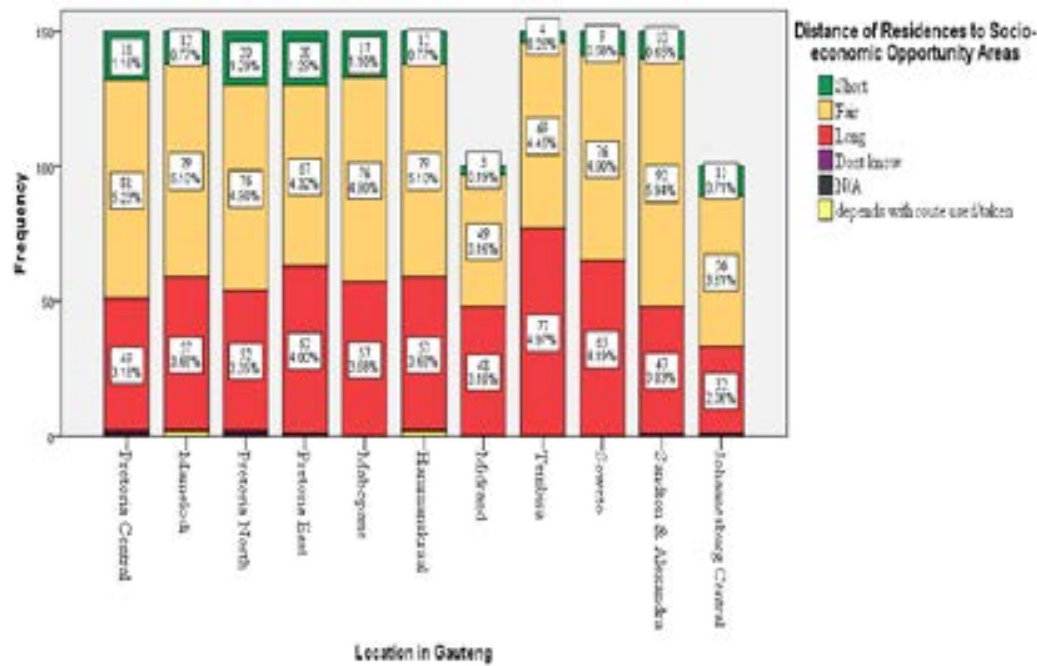

Fig. 3.

Distance of Residences to Socio-Economic Opportunity Areas

Source: (Study Findings, 2016)

Overall, commuters facing longest commuting times are located in Tembisa with 77 (49.7\%) of the 150 survey respondents in the location indicating that the average distance to socioeconomic opportunities areas took over 60 minutes travel time (i.e. long). This is followed by Soweto with 65 (41.9\%); Pretoria East with 62 (40\%); Mabopane 57 (36.8\%); Hammanskraal 37 (36.8\%); Mamelodi 57 (36.8\%). Save for Pretoria East, all the other settlements are low income peripheral areas which have long commuting distances to centres of opportunities. The poly-centric nature of Gauteng pulls people to Pretoria $\mathrm{CBD}$, Johannesburg CBD as well as $\mathrm{OR}$ Tambo International Airport. Regarding Pretoria East, despite the high car ownership the long commuting times are a reflection of the outcome of spatial fragmentation and scattering of socio-economic opportunities. The impact of this traverses all economic groups and residential places although it is much more pronounced in low and peripheral settlements. The highly dispersed, monofunctional land use layouts of cities adversely affect not only government systems but also residents (SACN, 2014). People have to travel long distances to and from places of work, which translates into higher travel costs and less time and money to spend on other social or recreational aspects that result in more fulfilled lifestyles (Chakwizira et al., 2011). The reality in South Africa is that many of the poorest people in urban areas live in the most peripheral locations of cities and are most disadvantaged by the long travelling distances (Shaw, 2006). Consequently, the urban development framework (UDF) discussion document highlights the enormity of the spatial challenge facing South African cities, stating that it is harder in 2013 to reverse apartheid geographies than it was in 1994 (Department of Cooperative Governance (DCoG), 2014). 


\subsubsection{Travelling Time to Socio-Economic Facilities}

Short travelling time was defined as a trip that takes between 0-15 minutes. Fair was described as a trip that took 16-59 travel time in minutes. Long was defined as a trip that took more than 60 minutes travel time. This categorization was adopted from the South African National Land Transport Strategic Framework 2006-2011 travel benchmark (Chakwizira, 2016). Overall, in terms of study findings respondents indicated that travelling (commuting) times to socio-economic areas was a challenge. 148 (9.5\%) of the 1550 surveyed respondents indicated that travel times was short (i.e. between 0-15 minutes). However $91.5 \%$ indicated that it was fair (i.e. 780 (50.3\%) to long (i.e. 621 (40.1\%). 1 respondent did not know about the duration of travel times. Typically low income peripheral areas had highest respondents noting that they experience long commuting times. In Tembisa the breakdown was as follows 77 (49.7\%) out of the sampled 150 respondents experienced long commuting times (i.e. exceeding 60 minutes), while 68 (43.9\%) had fair commuting travel times taking between 16-59 minutes. Only 5 (i.e. $3.2 \%$ ) indicated that the travel times was short (i.e. taking between 0-15 minutes travel time). In Soweto, Hammanskraal, Mabopane and Mamelodi the same pattern and trend is repeated. It is also worrying that the same patterns also manifest when one considers high income areas such as Midrand (i.e. 43 (27.7\%) noted that travel times exceeded 60 minutes, 53 (34.2\%) travel times took between 15 -59 minutes while $4(2.6 \%)$ of the trips took under 0-15 minutes travel time. This pattern is also reflected in Sandton and Pretoria East as examples. Overall, these results are corroborated by the NHTS, 2013 survey results (Chakwizira et al., 2014). The vast majority of the urban population i.e. the poor live in townships on the periphery of cities. As a result, the poor seeking to access economic opportunities located in cities bear an adverse financial and time burden. For instance, in 2013 it took more than an hour to get to work (including walking and waiting times) for $26.3 \%$ of taxi journeys, $52.7 \%$ of bus trips and $66.3 \%$ of train journeys, while $30.7 \%$ of those who walked took more than 30 minutes StatsSA (2014) The long commuting times are exacerbated by congestion in Gauteng freeways and road network systems. Congestion adds to delay given that traffic congestion on the Ben Schoeman has been increasing in intensity by roughly $7 \%$ annually for more than 10 years, and this trend is showing no signs of declining (Chakwizira, 2007). The travelling burden is faced most acutely by private motorists. In Gauteng province commuters who have a choice elect to use automobiles for commuting. Due to this, vehicle sales have risen annually between 1994 and 2005 by $25 \%$ (Shaw, 2006).

\subsubsection{Time that Commuters Leave Home for Work}

The survey respondents indicate interesting adaptation and commuting mitigations strategies that are being adopted as coping means of travelling in the context of rapid motorization and urbanization in Gauteng province. 21 (1.4\%) of the survey respondents left home before 05h 30.54 $(3.5 \%)$ of the survey respondents left home between $05 \mathrm{~h} 31$ and $06 \mathrm{~h} 00$ in the morning. The majority of commuters leave home between $06 \mathrm{~h} 01$ and $08 \mathrm{~h} 30$. However the distribution of movements is evenly distributed as follows: 279 (18\%) leave 
home from between 0601-0630 in the morning, while 233 (15\%) leave between 06031-07h00 in the morning. 361 (23.3\%) leave home from between 0701-0730 in the morning. Almost similar numbers leave thereafter. The result of this is some form of platooning of travel movement in Gauteng province.

More than one-quarter (29.6\%) of South Africa's workers left their home or area of residence for work between seven and seven fifty nine in the morning. Out of the $18.6 \%$ of workers travelling from six to six twenty nine in the morning, KwaZulu-Natal (21.9\%) had the highest level, followed by $20 \%$ reported in Gauteng, Limpopo and Mpumalanga. Twelve per cent of workers left their homes from eight o' clock in the morning or later when going to work. Western Cape (14.9\%) and Gauteng (13.5\%) recorded slightly higher levels of workers going to work from eight o' clock or later, while the distribution across all provinces was more or less equal (StatsSA, 2014). This is commuting adaptation to respond to commuting dynamics brought by congestion on the roads. (Lombard et al., 2007) indicate that in Gauteng commuters who drive have responded by either leaving very early between $05 \mathrm{~h} 30$ and $06 \mathrm{~h} 30$ or leaving slightly after 08h30 for work.

\subsubsection{Travel Interchanges}

$180(11.6 \%)$ of the survey respondents indicated that they had to make a travel change along the trip prior to reaching final destination. In addition, they felt that making more than 3 travel changes was too many travel changes for a trip. 691 (44.6\%) indicated that making two travel change during the trip was just right. This indicates that the commuters have got accustomed to travel change and view it as a normal part of trip making. 596 (38.3\%) did not make a travel change or made one travel change which was termed few by the respondents. This is consistent with the findings of the national household travel survey (NHTS), 2013. Nearly half a million workers, thus nearly half of all the workers in South Africa who changed transport, worked in Gauteng (StatsSA, 2014). Workers who change travel modes were $20.9 \%$ in the Gauteng. This constituted $46.9 \%$ in South Africa. In addition, almost $15 \%$ of workers who did not drive all the way to work indicated that they changed transport during the course of their journey. One-fifth of those who changed mode of travel worked in Gauteng (20.9\%), followed by Free State (17.9\%), Western Cape (15.5\%) and North West (15.2\%).Four out of ten $(57.6 \%)$ train users did not need to make any transfers while travelling by train. Fifteen per cent of commuters using buses and $12.7 \%$ of those using taxis had to transfer at least once during their trips. Most workers who made at least one public transport transfer used trains.

Although this percentage decreased from $54.7 \%$ in 2003 to $42.4 \%$ in 2013 , train users were still the most likely of all public transport users to make one or more transfer on their journey to work (StatsSA, 2014). Spatially, most commuters who indicated that the travel interchanges were too many were from Mamelodi (i.e. $33-2.13 \%)$ and Hammanskraal with similar statistics. Overall traditional high income areas respondents noted that travel interchanges were just right although the majority of these did not use public transport since they used private car. The high percentage of respondents from low income areas indicating that the travel interchanges were few may be 
a reflection of changes in spatial location in relation to the most appropriate travel means and socio-economic opportunity areas. In terms of travel interchanges by main travel mode, those who used mini-bus taxis and metro-rail indicated that there was too many travel interchanges. In addition, commuters are coping and avoiding travel changes through walking part of the trip. In addition, those who drive also indicated that travel interchanges were many. This is because most of them drive and park their cars to the first public transport pick-up point and will complete the journey using another mode.

\subsubsection{Traffic Congestion}

Survey respondents indicated that traffic congestion in Gauteng was high (i.e. 643 - $41.5 \%$ ), fair (i.e. 580 - 37.4\%). Only 307 $-19.8 \%$ of the survey respondents indicated that traffic congestion in Gauteng province is low. The survey results show that the spread and impact of traffic congestion is felt throughout Gauteng. The combination of urbanization, ailing and badly planned infrastructure and lack of public transport is increasing congestion on roads. Idling and stop-start activities result in more emissions than driving at higher speeds and this is typical of city style driving (Litman, 2010). It is acknowledged that the urban air quality in South Africa needs to improve and that transport emissions are a significant contributor, especially from the high emitting (old technology and poorly maintained) vehicles. However, low income areas residents indicated that in their areas congestion was low but high in the CBDs of Johannesburg, Pretoria and OR Tambo International Airport.

\subsubsection{Travel Time Index in Gauteng Province}

Travel time index (TTI) is the ratio of the average travel time during peak period to the travel time during off-peak period (Prevedouros, 2008). The TTI data was analyzed using mathematical computations and simple descriptive statistics in the form of percentages, mean, standard deviation, and maximum and minimum values (Mpogole and Samira, 2016). We also included some $95 \%$ confidence intervals for the mean in estimating TTI. TTI was estimated using Eq. (1) as the ratio of the average time taken to commute during the peak period and the travel time that would be taken to commute the same distance in free-flow (Eisele et al., 2011; Prevedouros, 2008).

$T T I=\frac{T_{\text {Jam }}}{T_{\text {NoJam }}}$

Where TJam is the average time taken to commute from the home bus stop during peak hours and TNoJam is the time taken to commute the same distance during off-peak hours (free-flow conditions). Transportation system performance can be measured by either vehicular speed or travel time (Eisele et al., 2011). According to (Eisele et al., 2011), travel time measures are consistent, address transportation and land use systems, and are responsive to concerns of residents, businesses and travellers. Moreover, TTI has been proven valuable mobility analysis and transportation system performance (Eisele et al., 2011). TTI can be described according to the ranges shown on Table 4. A TTI greater than or equal to 2.0 represents a very poor transport system with intolerable traffic jam and or congestion. 
Table 4

Travel Time Index (TTI) Description

\begin{tabular}{|c|c|c|}
\hline SN & Travel Time Index (TTI) & Description of Travel Time Index (TTI) Condition \\
\hline 1 & “ $\geq 2.0 "$ & "Very Poor" \\
\hline 2 & "1.6-1.9” & "Poor" \\
\hline 3 & " $\leq 1.5 ”$ & "Tolerable" \\
\hline
\end{tabular}

Source: (Mpogole and Samira, 2016)

Findings reveal that the average TTI for commuting from residences to various socio-economic opportunity areas was 2.35 . Gauteng TTI is $\geq 2.0$ highlighting that the transport system is inefficient although the transport system is functionally effective in distributing traffic and travellers along its spatial confines albeit with differentiated commuting access and constraints. The problems of access and constraints in Gauteng province South Africa can be traced to apartheid, which created the spatial bases that lead to spatial fragmentation, division and separation of areas along racial lines (Department of Transport, 2013). Consequently, the peripheral areas, low income and density areas are located at the edges making trip purposes expensive, resulting in long commuting hours for low income and peripherally located settlements (UITP, 2003; Kumar and Barrett, 2008; Department of Transport, 2013).

In Gauteng, the average travel time to work is 2.35 for shopping trips, 2.31 for all combined trips, 7.05 for College trips as well as 3.04 for the breadwinner's trip. This means that if the average travel time to work is 20 minutes when there is no traffic jam, then the average shopping commuter is spending 20 minutes $\mathrm{x}$ $2.35=47$ minutes to engage in the shopping trip due to a combination of the road conditions (traffic congestion), fragmented settlements and dispersed services. The college trip commuter who spends say 20 minutes to travel to School/College during free flow traffic conditions, currently spends $20 \times 7.05=141$ minutes during traffic jam or peak or congested periods. This translates to 2 hours 35 minutes which is valuable study time that would be lost. It is for this reason, why the majority of students either stays on campus or is prepared to pay high rent for flats to live near the campus premises. The actual family breadwinner who spends 20 minutes to arrive to the work place in the absence of traffic jams or congestion is currently spending $20 \times 3.04=60.8$ minutes during peak traffic conditions. This is one reason why urban commuters have responded by either leaving early prior to the peak period or delay leaving work so that they can avoid the evening peak travel challenges. The combined average travelling time in Gauteng is 2.31 and this means that for a trip that takes 20 minutes during a congestion free period, the average commuter is spending $20 \times 2.31=46.2$ minutes during peak periods. While previously the average commuter travelling time was over 65 minutes, the reduction can be attributed to the improvements in road expansion and construction in Gauteng under the Gauteng Freeway Road Improvement Programme. What is however interesting is that these improvements seems not to have had a big impact on scholar transport and travel which remains an area still requiring improvement. Gauteng's road network has to cope with an annual traffic increase rate of $7 \%$, with 1.8 million drivers and 2.8 million registered vehicles (Chakwizira et al., 2014). $40 \%$ of the 
national fleet and traffic has been increasing on the $\mathrm{M} 1 / \mathrm{N} 1$ corridor, roughly $7 \%$ a year over the past 10 years (Schmidt, 2006; Lombard et al., 2007). The average travel time to work in the Gauteng province has increased from 41.5 minutes in 1995 to 50 minutes in 2003, representing a $17 \%$ increase over eight years (Shaw, 2005). Distances and density are two important factors that influence public transport delivery and services. Altogether, distance and density determine the cost of public transport and, ultimately, influence affordability (Cervero, 2001). Distance and density frame the city's urban form (SACN, 2014). The average traveling time to work in metropolitan cities in Gauteng province has increased from 41.5 minutes in 1995 to 50.0 minutes in 2003, a 17 percent rise over eight years (Cox, 2005; Shaw, 2005). South African commuters spend roughly 1.5 - 2 hours commuting per day (Department of Transport, 2005). The average daily commute for a commuter set by the Department of Transport White Transport Policy of 1996 (currently under review) should be less than one hour one way, but it takes some 1.3 million public transport commuters longer than one hour to travel to work (Department of Transport (2010). This indicates inefficiency in time spent commuting, which has a negative impact on the quality of life and family time. Table 5 presents the TTI in Gauteng province for different trip purposes.

\section{Table 5}

Travel Time Index in Gauteng Province for Different Trip Purposes

\begin{tabular}{|c|c|c|c|c|}
\hline & $\begin{array}{c}\text { Approximate Time for } \\
\text { breadwinner's trip }\end{array}$ & $\begin{array}{c}\text { Approximate Time } \\
\text { for College Trip }\end{array}$ & $\begin{array}{c}\text { Travel Time for } \\
\text { shopping trip }\end{array}$ & $\begin{array}{c}\text { Generalized Travelling } \\
\text { Time in Gauteng } \\
\text { Province }\end{array}$ \\
\hline Number Valid & 1550 & 1550 & 1550 & 1550 \\
\hline Mean & 3.04 & 7.05 & 2.35 & 2.31 \\
\hline Std. Error of Mean & 0.050 & 0.108 & 0.048 & .016 \\
\hline Median & 3.00 & 11.00 & 2.00 & 2.00 \\
\hline Mode & 3 & 11 & 1 & 2 \\
\hline Std. Deviation & 1.950 & 4.254 & 1.888 & 0.636 \\
\hline Variance & 3.803 & 18.100 & 3.566 & 1 \\
\hline Minimum & 1 & 1 & 1 & 4 \\
\hline Maximum & 13 & 11 & 11 & \\
\hline Percentiles & 11.00 & 4.00 & 3.00 & \\
\hline
\end{tabular}

Source: (Research Findings, 2016)

Low-density sprawl and fragmentation were (are) characteristic of the Gauteng region contributing to access constraints and temporal spatial structural disjuncture that comprises challenges that Gauteng province is grappling to resolve (SACN,
2014). Studies and research have shown that establishing transport authorities in regions like Gauteng province such as experiences from Netherlands and France can contribute to enhancing commuting (Moeinaddini $e t$ al., 2012; UITP, 2015). 


\section{Recommendations}

\subsection{Addressing Urban Commuting Challenges in Gauteng Province}

Respondents were requested to indicate urban commuting solutions to addressing identified transport commuting affordability challenges. $38.5 \%$ of the respondents indicated that developing compact, smart and integrated urban land spaces was key to reducing travel challenges in the study area. $23.4 \%$ indicated that the introduction and upgrading of bus rapid transport (BRT) buses to cover all areas in the study area was a step in the right direction which has great potential in shifting travel patterns to favor public modes of transport. $15.1 \%$ indicated that all open spaces should be developed so that fragmentation of land uses can be addressed. This would help to fight disconnected and fragmented space and trip making challenges in the study area (Moeinaddini et al., 2012; Chakwizira et al., 2014; SACN, 2014). 13.4\% indicated that improving the metro rail services was critical since this is a mass mover of commuters. $9.6 \%$ of the respondents highlighted that the bus subsidy policy has to be retained at least for now since the spatial mismatches and challenges created by apartheid are yet to be fully reversed.

\subsection{Distance of Homes from Socio- Economic Opportunities}

Suggested solutions to address the fragmented city structure of the study area are varied and diverse as indicated by the survey respondents (Harrison et al, 2008). $33.1 \%$ of the respondents indicated that a compact design was the solution. $27.3 \%$ of the respondents highlighted that transit orientated developments have to be fostered and promoted in the major transport corridors in Gauteng (SACN, 2014). 16\% noted that there was room for mixed use zoning to contribute regarding minimizing trip making. The BRT ate $10.1 \%$ was the highest public transport intervention viewed as having potential to address the problem of separated socio-economic developments in the study area (Department of Transport, 2011). Gautrain and light rail at $0.7 \%$ and $0.8 \%$ were seen as least initiatives to assist in reducing the problems.

\subsection{Travelling Time Solutions}

One major identified commuting challenge was that commuters are spending a lot of time travelling (Cervero, 2001). Respondents were asked to indicate which travelling time solutions they thought if implemented can address this matter. $44 \%$ indicated that dedicated BRT busways was the solution. It was argued that international cases existed to support this notion. $26.9 \%$ indicated that employers needed to explore and use the concept of flexi hours much more as with Information Technology it is now possible to work from home and have virtual offices rather than be office bound (Harriet et al., 2013; Tadić et al., 2015). At $6.1 \%$ respondents felt that scope for the light rail needed further thought as it can be a cue for the travelling time challenges. $3.3 \%$ of the respondents indicated that an underground transport system for Johannesburg needed to be constructed (Chakwizira, 2007). This was the case in all developed countries. $2.8 \%$ indicated that if Gautrain is fully developed and extended to all parts of the Province it can play a significant role in addressing the challenge (Department of Transport, 2011). 


\subsection{Traffic Congestion Challenge Solutions}

One of the identified problems that commuters are facing is traffic congestion (Mpogole and Samira, 2016; Jain et al., 2016). Respondents indicated a range of options and strategies that could be implemented to address this challenge. $22.3 \%$ indicated that a compact city development form would go a long way in addressing this challenge. This would reduce the need for motor based trips as people could easily walk to various socio-economic areas. BRT systems at $19.9 \%$ were a prime improvement target area. Mixed use developments at $16.2 \%$ were also an integral part of solutions advanced. Introduction of a car retirement policy at $15.2 \%$ was seen as an important policy area (Department of Transport, 2010). The Johannesburg underground transport system at $7.1 \%$ was also seen as a serious contender. Car ownership policy with capping was viewed as important at $5.1 \%$. Improving the Gauteng freeways at $8.1 \%$ featured as a prominent priority intervention area (Gauteng Department of Roads and Transport, 2013). Implementing a wide suite of measures is what will make a lasting impression in addressing traffic congestion in the study area.

\subsection{Spatial Targeting and Decentralization}

Spatially job density is highest in the triangle of Johannesburg CBD, Tshwane CBD and the Aerotropolis region in Ekurhuleni (Department of Transport, 2007). This has resonates with the need to identify and develop local economic opportunities for industrial establishment and expansion in previously marginalised areas such as Mabopane, Hammanskraal and KwaThema as examples (Chama, 2013). Such an approach will bring "opportunities and jobs" closer (i.e. at their doorsteps instead of far over and yonder) to the current cluster of commuter "who faces the greatest travail and anguish of long travelling times and distances including loss of family time" (SACN, 2014; Tadić et al., 2015).

\subsection{Different Transport Strokes for Different Transport Folks: a Rejoinder}

The preceding discussion on public transport commuting challenges in Gauteng province, South Africa indicates the existence of different transport strokes for different transport folks. Different transport strokes are hitting, striking and blowing public transport commuters. The impacts of the strokes or blows change over time, place, space, scale, intensity and at times take a spatio-temporal dimension. Consequently, interventions and measures aimed at addressing the different public transport commuting strokes for different transport folks will require integrated, collaborative and multi, cross, trans and inter-disciplinary inputs from various stakeholders in the society. Given the apartheid fragmented spatial geography of Gauteng province cities, public transport commuters are hit, struck and blown by transport strokes of long commuting times ( $51.6 \%$ of the sampled respondents) and long commuting distances ( $40.1 \%$ of the sampled respondents). This is because of the mismatch between residential areas especially low income and peripheral settlements that are located far away from socio-economic opportunities. In addition, commuters have added transport strokes in terms of congestion (41.5\%), accidents, road rage, shouldering the costs of the recently introduced "e-tolls", travel interchanges $(44.6 \%)$. In order to address and treat different transport strokes for the different 
transport folks, respondents indicated that re (engineering) and spatial transformation of settlements from the apartheid fragmented design to a post-apartheid universal, smart and integrative settlement design is one possible approach (38.5\%). In terms of overcoming the distance stroke barrier - respondents suggested that a mixture of packages including transit orientated developments (ToDs), Compact City design, bus rapid transport (BRT) etc. can assist in reversing and overcoming distance based transport strokes for different transport folks. Regarding travelling solutions, respondents indicated that promoting BRT and possibly various tube based mass transit systems was the way to go. Overall, the need for robust spatial targeting and decentralization of functions and industries was suggested as another way of tackling locational disadvantages induced transport strokes for public transport commuters, operators and policy makers alike. Table 6 summarizes the different transport strokes for different transport folk's conceptual framework of analysis.

\section{Table 6}

Different Transport Strokes for Different Transport Folks Framework of Analysis

\begin{tabular}{|c|c|c|c|c|c|c|}
\hline \multirow[b]{2}{*}{ Typologies } & \multicolumn{6}{|c|}{ Dimensions } \\
\hline & Spatial strokes & $\begin{array}{c}\text { Long } \\
\text { commuting } \\
\text { times strokes }\end{array}$ & $\begin{array}{c}\text { Long } \\
\text { Commuting } \\
\text { distance strokes }\end{array}$ & $\begin{array}{l}\text { Commuting } \\
\text { behaviour } \\
\text { adaptation }\end{array}$ & $\begin{array}{c}\text { High } \\
\text { Environmental } \\
\text { costs strokes }\end{array}$ & $\begin{array}{c}\text { High } \\
\text { transportation } \\
\text { costs strokes }\end{array}$ \\
\hline Impacts & $\begin{array}{c}\text { Fragmented } \\
\text { transport } \\
\text { systems; } \\
\text { disconnected } \\
\text { settlements; } \\
\text { poly and multi- } \\
\text { centric dispersed } \\
\text { settlements; } \\
\text { elongated and } \\
\text { circuitous trips }\end{array}$ & $\begin{array}{c}\text { Increased risk } \\
\text { of fatigue and } \\
\text { accidents; } \\
\text { increased motor } \\
\text { based pollutants } \\
\text { emitted; social } \\
\text { challenges; poor } \\
\text { transport levels } \\
\text { of service (LOS) }\end{array}$ & $\begin{array}{l}\text { Multiple trips; } \\
\text { Truncated trips; } \\
\text { re-location; } \\
\text { multiple } \\
\text { residences; } \\
\text { social and } \\
\text { family cohesion } \\
\text { matters }\end{array}$ & $\begin{array}{l}\text { Road rage; Road } \\
\text { bullying; early } \\
\text { departure; late } \\
\text { arrival and early } \\
\text { departure and late } \\
\text { departure from } \\
\text { work; employee } \\
\text { productivity } \\
\text { compromised }\end{array}$ & $\begin{array}{l}\text { Carbon emission } \\
\text { risk related } \\
\text { illness; urban } \\
\text { heat island } \\
\text { effects; climate } \\
\text { change response } \\
\text { and target } \\
\text { inadequacies }\end{array}$ & $\begin{array}{l}\text { High percentage } \\
\text { of family income } \\
\text { expenditure } \\
\text { on transport; } \\
\text { potential savings } \\
\text { on transport } \\
\text { unavailable for } \\
\text { family needs; } \\
\text { household } \\
\text { livelihood } \\
\text { challenges }\end{array}$ \\
\hline Interventions & $\begin{array}{c}\text { Integrated } \\
\text { Settlements; } \\
\text { TA for Gauteng } \\
\text { Province; } \\
\text { Political Will; } \\
\text { Adaptive } \\
\text { Governance } \\
\text { Transport } \\
\text { Structures and } \\
\text { Systems }\end{array}$ & $\begin{array}{c}\text { Mixed } \\
\text { Development; } \\
\text { Road Pricing; } \\
\text { car Ownership } \\
\text { Policy; Public } \\
\text { Transport Key } \\
\text { Performance } \\
\text { Indicators } \\
\text { (KPIs) }\end{array}$ & $\begin{array}{c}\text { Compact } \\
\text { Design; ToDs; } \\
\text { BRT; Transport } \\
\text { Authority } \\
\text { for Gauteng; } \\
\text { Integrated } \\
\text { Ticketing } \\
\text { System }\end{array}$ & $\begin{array}{l}\text { Car Parking } \\
\text { Restriction } \\
\text { Policy; Road } \\
\text { Pricing and } \\
\text { Tolling; } \\
\text { Congestion } \\
\text { Pricing; Viable } \\
\text { Public Transport } \\
\text { Alternatives; } \\
\text { Flexi-Hours }\end{array}$ & $\begin{array}{c}\text { Incentives for } \\
\text { Energy Efficient } \\
\text { (EE) Transport } \\
\text { Technologies } \\
\text { and Alternatives; } \\
\text { Car Retirement } \\
\text { and Ownership } \\
\text { Policies }\end{array}$ & $\begin{array}{c}\text { Subsidies; BRT; } \\
\text { Tube Transport; } \\
\text { ToDs; Spatial } \\
\text { targeting; } \\
\text { Decentralization; } \\
\text { Competitive } \\
\text { Franchising; } \\
\text { Compact City } \\
\text { Designs }\end{array}$ \\
\hline
\end{tabular}

Source: (Author's own conceptualisation, 2017)

\section{Conclusion}

Transport planning and management in Gauteng faces challenges that relate to space fragmentation which affect service delivery, funding requirements to improve, build and extent universal urban transport infrastructure and services in area of remit, integration of transport modes including the ticketing and fare structure as well as the problem of scattered functions and responsibilities by spheres of government. 
The combined impact of "ad -hoc" and incremental measures to address commuting problems is that "different transport folks face different transport strokes" that are deepening and widening irrespective of income group or spatial locations. The challenges of traffic gridlock, road rage, long commuting times, loss of productive hours, traffic congestion, accidents and emissions are transversal problems that cut across spatial scales, sectors and organizational hierarchies thereby tying us together to seek integrated and comprehensive solutions. The main commuting constraints and challenges cover all facets of the economy and society which implies the need for integrated solutions and responses. In order to "reverse the different strokes for different transport folks it is necessary to address various delivery and performance bottlenecks that lead to constrained transport commuting in Gauteng Province" (Silverman, 2007; Chakwizira, 2017). These can be summarized precisely as follows, namely:

- Adequate financial provisioning to meet public transport commuting projects and interventions requirements: Financial resources remain one of the main constraints in Metropolitan and District Municipalities to fulfil their obligations in terms of public transport commuting interventions (Chakwizira, 2017; Šimecki et al., 2013). The problem can be appreciated better if one notes that in South Africa investment in road infrastructure has on average decreased by $1 \%$ annually since 1975 (Department of Transport (2011). Financial constraints surrounding the maintenance and operation of ambient monitoring stations; conducting oversight studies as well as implementing a package of integrated transport planning and spatial turn measures is hamstrung by lack limited resources (Office of Science and Technology, 2006). Financial resources are essential to ensure the successful implementation and enforcement of sustainable Gauteng public transport agenda (Moeinaddini et al., 2012).

- Dynamic transport authority and progressive public commuting leadership: Inter-governmental and inter-departmental communication and cooperation are major constraints in ensuring successful public transport commuting constraints reduction and reversal (Chakwizira, 2017; Balya et al., 2016). Without the mutual understanding between related departments such as land-use planning, road infrastructure development, urban zoning and air quality management public transport and land use commuting orientated intervention and strategies are setup to fail at the implementation phase (Hjaltested, 2012). This also applies to the inter-governmental linkages between municipal and provincial government where synergy is essential. A holistic approach which goes over the constraints of the "silo based approaches" despite the existence of the municipal inter - structures coordinating act is therefore needed in the transport and spatial related growth and development management strategies (Jain et al., 2016; Tadić et al., 2015).

Overall, the political will to ensure that public transport commuting is a top priority in municipal, provincial and national budgets is a key debating point if differentiated access and constraints strokes for different folks is to be ameliorated. In addition, there is need 
for political leadership regarding linking public transport commuting matters to leading themes such as Climate Change strategies and identifying the co-benefits so as to ensure that there is a bigger dragnet for attracting funding for public transport commuting projects implementation.

\section{References}

Balya, M.I.; Katti, B.K.; Saw, K. 2016. Spatial transit accessibility modeling of Indian metropolitan city in GIS environment, International Journal for Traffic and Transport Engineering 6(1): 51-62.

Bertaud A. 2008. International comparisons: spatial development and poverty. In International Urban Development Workshop.

Bertaud, A. 2004. The Spatial Organization of Cities: Deliberate Outcome or Unforeseen Consequence?. World Bank, Washington, D.C. USA. 28 p.

Cervero, R. 2001. Integration of urban transport and urban planning, in Mila Freire and Richard Stren (eds.) The Challenge of Urban Government: Policies and Practices. Washington, D.C.: The World Bank, 407-427.

Chakwizira, J.; Mashiri, M. 2009. The contribution of transport governance in socio-economic development in South Africa. In Proceedings of the Southern African Transport Conference (SATC), Sustainable Transport: 28th Annual Southern African Transport Conference (SATC) 2009, 1-18.

Chakwizira, J. 2007. The Question of Traffic Congestion and Decongestion in the Greater Johannesburg Region. In Proceedings of the Southern African Transport Conference (SATC), 499-511.

Chakwizira, J. 2016. Access and constraints to commuting in Gauteng province, South Africa. $\mathrm{PhD}$ unpublished Thesis, University of Venda, Thohoyandou, South Africa.
Chakwizira, J. 2017. Transport modelling research agenda and new directions: Evidence from a developing country, in Ilsa Schoeman (Eds) Transportation, Land Use and Integration: Applications in Developing Countries, Volume 100 of WIT Transactions on State-of-the-art in Science and Engineering, 95-118.

Chakwizira, J.; Bikam, P.; Adeboyejo, T.A. 2014. The Impact of Rapid Urbanisation on Public Transport Systems in the Gauteng Region of South Africa, International Journal of Humanities and Social Sciences 8(5): 564-575.

Chakwizira, J.; Bikam, P.; Dayomi, M.A.; Adeboyejo, T.A. 2011. Some Missing Dimensions of Urban Public Transport in Africa: Insights and Perspectives from South Africa, The Built and Human Environment Review 4(2): 56-84.

Cox, A. 2005. Shilowa's R20bn silence in The Star. Available from internet: <http://www.thestar.co.za/ index.php?fArticleId $>$.

CSIR. 2010. 7th Annual state of logistics survey Value creation towards global competitiveness and sustainability. Pretoria, South Africa. Available from internet: <http://dev.sdklab.com>.

DCoG (Department of Cooperative Governance). 2014. MIG policy framework review. In National Consultative Workshop, 1-25.

Department of Transport. 2005. National Freight Logistics Strategy. Pretoria. Government Printers. South Africa. 61p.

Department of Transport. 2010. National Transport Master Plan: NATMAP 2050. Department of Transport. Pretoria, Government Printers. South Africa. 492 p.

Department of Transport. 2011. NATMAP 2050 Consolidated Agenda for Action Report (inclusive of Provincial Reports). Pretoria. Government Printers. South Africa. 492 p. 
Department of Transport. 2013. South African National Household Travel Survey. Pretoria, Government Printers. South Africa. 179 p.

Eisele, W.; Zhang, Y.; Park, E.S.; Zhang, Y.; Stensrud, R. 2011. Developing and applying models for estimating arterial corridor travel time index for transportation planning in small to medium-sized communities, Journal of the Transportation Research Board 2244: 81-90.

Gauteng Department of Roads and Transport (GDRT). 2013. Gauteng 25-year Integrated Transport Master Plan: 12 August 2013-DraftPlan. Gauteng Provincial Government. Johannesburg. South Africa.193 p.

Harrison, P.; Todes, A.; Watson, V. 2008. Planning and Transformation. Lessons from the South African Experience. London: Routledge. 301 p.

Hjaltested, A. B. 2012. Sustainable Urban Future of Reykjavik: The case of Artunshofdi, MSc Thesis, Department of Management Engineering. Technical University of Denmark. 245 p.

Jain, U.; Sarkar, P.; Vibhuti, A. 2016. Potential of Personal Rapid Transit System to Meet the Urban Transport Deficit, International Journal for Traffic and Transport Engineering 6(3): 313-324.

Kumar, A.; Barrett, F. 2008. Stuck in Traffic: Urban Transport in Africa. World Bank, Washington, DC. USA. 103 p.

Litman, T. 2010. Sustainability and Liveability, Summary of Definitions, Goals, Objectives and Performance Indicators. Victoria Transport Policy Institute. Australia. 5 p.

Litman, T.; Burwell, D. 2006. Issues in sustainable transportation, International Journal of Global Environmental Issues 6(4): 331-347.
Lombard, M.; Cameron, B.; Mokonyama, M.; Shaw, A. 2007. Report on trends in passenger transport in South Africa. Midrand: Development Bank of South Africa. 128p.

Moeinaddini, M.; Shekari, Z.A.; Shah, M.Z. 2012. The effectiveness of private motorized trips indicators in reducing car usage, International Journal for Traffic and Transport Engineering 2(4): 347-358.

Mpogole, H.; Msangi, S. 2016. Traffic Congestion in Dar es Salaam: Implications for Workers', Journal of Sustainable Development 9(6): 103-110.

Office of Science and Technology. 2006. Foresight Intelligent Infrastructure Futures: The Scenarios - Towards 2055. London. UK. 89p.

Prevedouros, P. D. 2008. Transportation alternatives analysis for mitigating traffic congestion between Leeward Oahu and Honolulu. University of Hawaii at Manoa. 130 p. Available from internet: <http://www. honolulutraffic.com/UHCS_Report41.pdf $>$.

SACN. 2011. State of the Cities Report. The South African Cities Network (SACN). Braamfontein. Johannesburg. South Africa. 416 p.

SACN. 2014. From Housing to Human Settlements: Evolving Perspectives. Braamfontein. Johannesburg. South Africa. $320 \mathrm{p}$.

Schmidt, M. 2006. Gridlock Deadlock in The Saturday Star. 4 November 2006. 15 p.

Shaw, A. 2005. Public Transport: Gautrain Can Show Way For SA, Business Day. 11 p.

Shaw, A. 2006. Achieving a pro-public transport agenda in South Africa- the challenge for middle income countries, WIT Transactions on the Built Environment 89: 805 -815.

\section{jitte 80}


Shrank, D.; Eisele, B.; Lomax T. 2012. Urban Mobility Report. Texas. USA. 68 p.

Silverman, E. 2007. Families and urban regeneration: The case of mixed income new communities in the UK, PhD, Department of Social Policy, London School of Economics, UK. 384 p.

Šimecki, A.; Steiner, S.; Čokorilo, O. 2013. The accessibility assessment of regional transport network in the South East Europe, International Journal for Traffic and Transport Engineering 3(4): 351-364.

StatsSA. 2014. National Household Travel Survey. Pretoria: Statistics South Africa. Government Printers, South Africa. $109 \mathrm{p}$.

Tadić, S.; Zečević, S.; Krstić, M. 2015. City LogisticsStatus and Trends, International Journal for Traffic and Transport Engineering 5(3): 319-343.
UITP. 2003. Better Mobility in Urban Areas. Rue SainteMarie 6, BE - 1080. Brussels. Belgium. 44 p.

UITP. 2006. Public Transport in 2020: From Vision to Action. Rue Sainte-Marie 6, BE - 1080. Brussels. Belgium. 27 p.

UITP. 2012. Mobilities in Cities database. Rue Sainte-Marie 6, BE - 1080. Brussels. Belgium. CD-ROM format.

UITP. 2015. Public Transport Driving Europe Forward in 2014-2019. Rue Sainte-Marie 6, BE - 1080. Brussels. Belgium. 4 p.

Vivier, J. 2006. Mobility in Cities Database. Better Mobility for People World Wide. Analysis and Recommendations. Brussels: International Association of Public Transport. $66 \mathrm{p}$. 